\title{
Design as externalization
}

\section{Enabling research}

Keywords: data visualization, design methods, design research, prototyping, externalization, digital humanities

The article is concerned with a central contribution of designing to information visualization in the digital humanities. The activity is characterized as one of externalization, instantiation in visible or tangible form of ideas. A spectrum of different interpretations of this process in the existing literature is discussed. The arguments are illustrated with recent practical examples from the authors' own work in designing with a range of cultural organizations. The article concludes with reflections on how projects may best benefit from this work of design, empowering the designer as a co-researcher, alongside the historian, curator or other humanities scholar.

\section{Introduction}

Our concern in this paper is with the contribution of designing, considered as an activity with associated experience and skills, to information visualization. In this paper, when we use the term designer, we are referring to someone taking on a particular role within projectsperhaps combined with other roles-not someone with a particular disciplinary pedigree. Within the many aspects of designing that might be discussed we focus on one: the devising of early mock-ups, prototypes and examples as a means of progressing the design process. In this article we use these terms loosely, referring to artifacts from low to high fidelity and of different media (Rudd, Stern, \& Isensee 1996). We treat such activity as one of externalization, that is the instantiation in visible or tangible form of ideas that might otherwise be internal to the minds of the designer and other participants. We note several characterizations of this process that have been discussed by other authors, including in some key early texts from the time when information design and design research were emerging as identifiable fields. We then describe, with recent practical examples, our own processes of designing with a range of cultural organizations-museums and archives-focusing on the role of such early-stage designing in the refinement and development of a range of data-visualization solutions. It perhaps seems superfluous to discuss the roles of visual externalization for readers of this journal, but we believe it is important to anatomize and reflect on such roles-not only because of the implications for how projects should best be conceptualized and conducted, but also to support the ambition that design should be an equal contributor to research.

The visualizations discussed here share some characteristics. They are concerned with nominal data, which 
names and describes (through cataloguing) a quantity of individual objects within collections; and we emphasize the interpretive power of organizing such objects according to time, in chronographic visualizations or timelines. Dörk, Pietsch, and Credico (2017: 41) note how pervasive the time attribute is in cultural collections, while Kräutli (2016: 22) elucidates differences between timelines used merely as devices for linear storytelling and as tools for visual analysis, prioritizing - as we do-the use of visualized time as a means of sense-making (p. 70-75). We do not focus on quantitative change over time but on other factors.

In the present article we use our own work to illustrate different uses of externalization. Whitelaw (2015) and Dörk, Pietsch, and Credico (2017) should also be consulted, particularly in relation to the use of visualization to open up cultural data to a range of users. While our examples are confined to data visualization, we believe that our observations may help to illuminate designing in other fields while at the same time identifying the history of some key theoretical contributions to this topic.

Our concern here is with the relatively narrow question of the visual expression of data and concepts, set within a critical approach. Our enumeration of the purposes of making is relevant not just to the disciplines of information visualization and design, but also to the digital humanities. This last discipline increasingly recognizes artifacts, tools, technologies and the processes of their making as substantive intellectual interventions rather than mere mechanisms, questioning the historically "higher status of interpretation, analysis, and abstraction over fabrication, application, and production" (Thompson Klein 2017). This has been described as a "maker turn", where "meaning is derived from thinking with objects"- "interpretive objects"-and where embodiment is "an integral part of how meaning is made" (Staley 2017). The visual, its production and use, which are central concerns of the Information Design Journal, are increasingly recognized within other disciplines that have traditionally been dominated by the word. The present article may therefore serve as a useful bridge between disciplinary debates.

\section{Externalization as self-expression}

From the rise of romanticism in the early nineteenth century, artists have been encouraged to express their emotions, world-view and other internal states through their art, and in the twentieth century this privilege has been extended to a few star designers. However, for the vast majority of those engaged in designing, this is not an aim. This is perhaps particularly the case in fields such as data visualization, where the designer is normally expected to make themselves as inconspicuous as possible, memorably metaphorized in relation to typography by Warde in 1932 through the term "crystal goblet", the vessel that presents rather than obscures or distracts from its content (Warde 2009). Nevertheless Jänicke (2016) discerns a perhaps increasing mismatch between the expectation of novelty in computer science visualization and the often modest demands of humanities scholars: the latter's objective is interpretive power rather than technical virtuosity. In our own work, we do not set out to impress with complex visuals but rather to assist museums and archives to use the simplest possible visual means to discover new knowledge about their collections and/or to engage their visitors and other clients with such knowledge.

\section{Externalization as cognitive support}

A wealth of theory engages with this important activity. In this mode, external representations act as a kind of prosthesis for the mind, discussed by Norman (1991) in terms of the "cognitive artifact" and by Scaife and Rogers 
(1996) as "external cognition." Such external support for mental operations is not limited to visualization in the generally accepted sense of the term: writing and text, as Ong (1982), Havelock (1986) and Goody (1987) make clear, also enable the mind to do work that would otherwise be difficult or impossible. The idea of computational media as mental prosthetic is fundamental to the innovations of Bush (1945), Engelbart (1962), Nelson (1974) and Berners-Lee (1989), as the title of Engelbart's essay "Augmenting Human Intellect" implies. In the memorable phrase of Spivey (2007: 264), when arguing a dynamic model of perception and cognition, "an environment is essentially doing some of the thinking for the person within it." Noël (2014) advances the value of diagramming as such an external artefact, particularly in relation to complex issues, emphasizing the iteration of diagrams within a cycle of increased understanding. Cognitive artifacts are a special case of Vygotsky's psychological tools, "physical objects made by humans for the purpose of aiding, enhancing, or improving cognition" (Hutchins 1999: 126). To mention Vygotsky is immediately to suggest that these external representations do not solely augment the abilities of the author, but are shared-and therefore social-representations, a point to which we return later in the article.

\section{Externalization as feedback}

Visser argues that the activity of designing is fundamentally concerned with cognitive artifacts since each tentative representation not only captures the current state of a design, but also implies directions for further development (Visser 2006: xvi). This recalls Arnheim's descriptions of sketches as "guiding images" whose role as externalization facilitates the design process as much as being an end in itself. A sketch may be tentative, generic and vague but this is a strength, since these qualities mean that it "stands for a whole range of possibilities without being tangibly committed to any one of them" (Arnheim 1993). Arnheim built on the observations of Goldschmidt (1991) who had specifically highlighted the dialogical role of such representations; the designer makes, observes, remakes, in an ongoing loop of action and reaction. Glanville and Pak (2010) particularly argue the model of conversation-an interactive, developmental activity. Their work unites Glanville's lifelong engagement with cybernetics (in particular its emphasis on the dynamic, productive, ever-changing interaction between people and things), Pask's conversation theory (Pask, Kallikourdis, \& Scott 1975), and Schön's reflective practice (Schön 1983).

Iterative externalization is so common in the design world that we tend to take it for granted; it just seems to be part of what we do. In our own recent projects, the iterative feedback process between maker and artifact is exemplified in Figure 1. The visualization project from which these prototypes/mock-ups derive aims to balance focus and context (Cockburn, Karlson, \& Bederson 2009) exploring historical image datasets, supporting comparison of images from different times. Multiple levels of timelines offer "zoomed in" views on different time periods from which a sample of individual images are displayed at a large enough size to be inspected (Vane 2019). Here, the designer is working primarily alone, trying out a range of solutions; strategies to balance focus and context were explored through a cycle of make-reflect-remake. This is a standard process within any competent designing, and one in which two overlapping activities typically take place: the designer improves the fit of the emerging design to various aspects of the requirements, but also uses the external representation as a jumping-off point for new ideas, perhaps simply to conceive and trial new solutions, but potentially also to reconsider the original "question". 

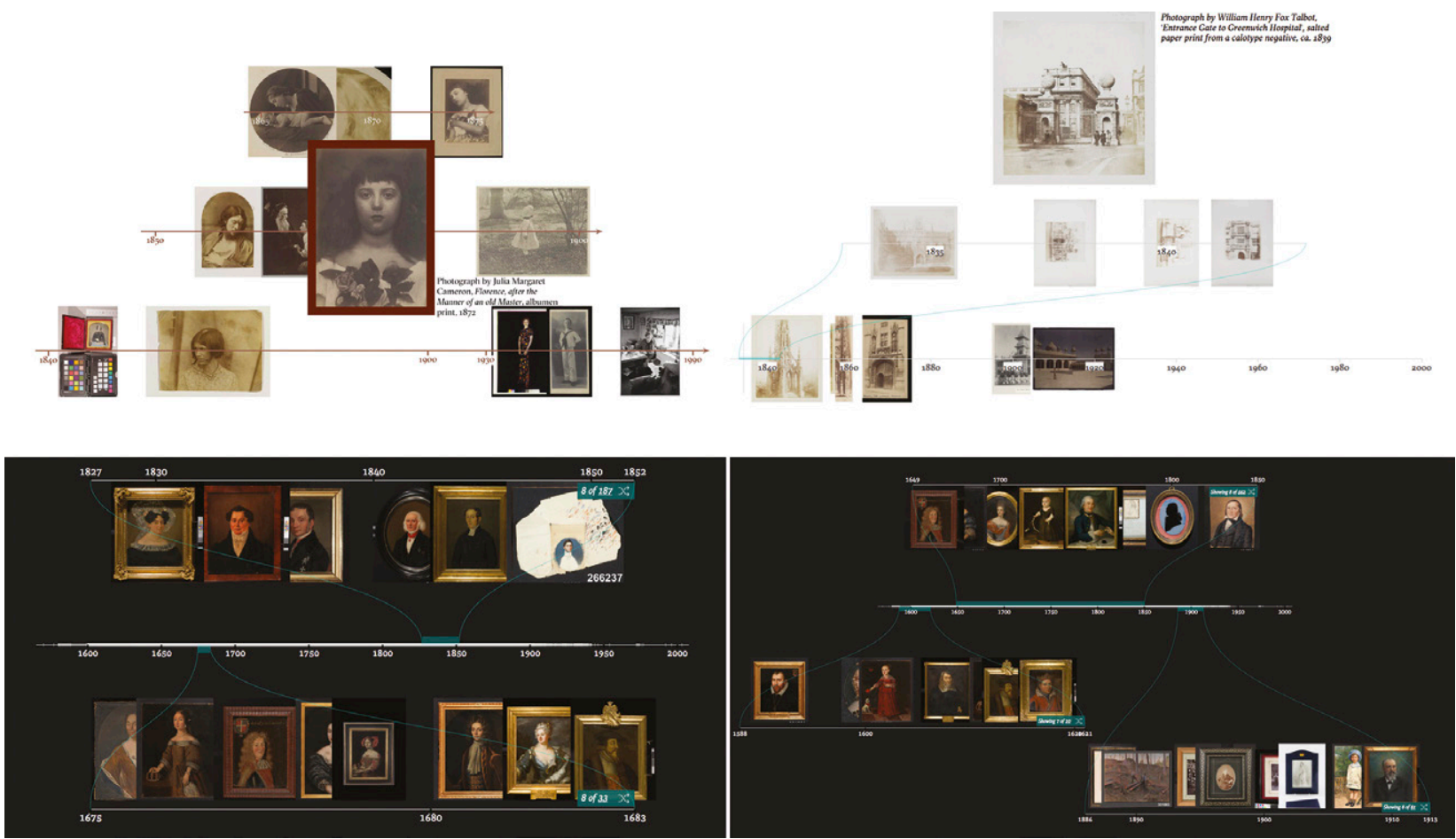

Figure 1. Olivia Vane, 2018. Exploring spatial and other visual variables to articulate a range of attributes and relationships in the Royal Photographic Society collection, Victoria \& Albert Museum, London (above) and in portraits in the Nordic Museum, Stockholm collection (below).

While our goal in this project was simplicity, many different algorithmic approaches to sampling the images were tried in an exploratory make-evaluate cycle. A distinctive feature of design-through-coding, as here, is that the results of changes cannot always be anticipated as feedback is not completely instantaneous. An implication of this iterative process is that the designer must be open to exploring an idea through a range of subtly or radically different representations. If, as is standard in information design and data visualization, the design is required to express a number of variables, such as date, degree of connection, certainty, category, etc., it is easy to exhaust the available graphic variables of hue, tone, texture, dimension, etc. (Bertin 1967, MacEachren 2001). Hard choices and compromises must be made, and new variations attempted. In the process the designer is highly attentive to the externalization, looking perceptively at, and reacting to, the emerging design, evaluating its effectiveness, seeking compromise between (and indeed re-balancing) requirements_-"satisficing" (Simon 1956). It is this process that makes learning to see or to look a key skill for designers. 


\section{Externalization as conversation}

The dialogic or conversational model of designing through tentative making can be conceived as a single, if powerful, feedback loop between the maker and the emerging artifact. But of course, rarely if ever is design an engagement by a solitary individual. Tentative designs will typically be subject to interactions involving colleagues, clients, manufacturers, programmers, end-users and a range of other stakeholders. In user-centered design, users may be consulted and tentative designs may be trialed. The emphasis will, in some cases, be on functionality, but increasingly on broader user experience. In participatory design, users have a significant role in the development cycle. Their experience and opinions are valued beyond merely reacting to proposed designs; while in co-design, users are experts for whom designers may conceive their own role as that of facilitator, altering the balance of power in favor of the user. Not only are power-relations different in these three models-usercentric, participatory and co-design-there are also implications for how early the user is involved in the journey from initial ideation. In all these cases, the production of tentative designs is an essential component, and the communicative or provocative character of such artifacts extends more broadly. Specifically in data visualization, Lloyd \& Dykes (2011) show how "data sketches" (rapid prototypes made with real data) allow the designer to engage usefully with stakeholders. Stevens (2013) draws attention to the formative role of designs within the day-to-day activities and strategies of the non-designers with organizations. He builds on the work of Crilly et al. (2008) who had earlier analyzed the multivalent role of artifacts as communicative objects. Kimbell (2011) calls for design to be re-characterized as a situated, contingent set of practices carried out between designers and those who engage with designers' activities - in other words, as a profoundly social, non-solitary activity.
As we have indicated, making low-fidelity prototypes early in a project, even before the designer feels they fully understand the task, can help them better understand challenges in the space they are working; dialogue is elicited through making. Our example in this case concerns a project visualizing a historical photographs collection, The Royal Photographic Society (RPS) collection, at the Victoria and Albert (V\&A) Museum, London. At the time of writing, the RPs collection was being digitized. Approximately 5,500 items had been digitally catalogued, and 2,500 had been photographed at the time of our collaboration.

We began our design process making rough plots laying out the collection data to get a better sense of what the collection consists of, how it distributes in time, and what attributes might be interesting to visualize. This came as a surprise to our partners at the museum, who had expected us to take our time familiarizing ourselves with the photographs rather than diving into making. Our activity, almost instinctive at the time, mirrored the argument in the literature cited, namely that of defining and redefining the question, problem or issue through externalization. As is so often the case, the process of making these visualizations progressed through several of the stages we have described. In its earliest form it was a cognitive support, allowing the designer to visually explore the data and have ideas that would be difficult or impossible without making. Later it was a node in the familiar feedback loop, where iterated variants of the emerging idea supported a cycle of making, thinking and re-making, probing different parts of the potential design-space. Finally it became externalization as conversation, the aspect emphasized by van Amstel at al. (2016) when they argue the social production of design space as a socio-material rather than a cognitive process. We would suggest that externalization retains its early cognitive and feedback roles even when enmeshed in social, collaborative processes: it is a well from which 
the designer draws continuously as well as a location for dialogue. The externalization affords multiple actions and interactions.

As the RPS visualization developed, we plotted the data by time and a range of other relationships offered by the dataset-separating the data by photographer, by photographic technique, and by theme (Figure 2 ). Through discussing these rough plots with staff at the museum, we quickly realized the shapes revealed by visualizing the collection this way were greatly skewed by what items had been prioritized for digitization. Only about $2 \%$ of this collection had been digitized at the time and the biases in those choices were overshadowing larger historical trends. These plots also revealed that some plentiful but similar types of photographs, such as widely-produced portraits, were overwhelming other content. The tendency for visualization to reveal as much about the internal practices of the institution, as about the collection considered in the abstract, is discussed by Kräutli (2016: 147 fol.). In the words of Bailey and Pregill (2014), "visualization serves to place the individual item within the context of both the larger collection and the evolution of the institution itself." Kräutli went on to use visualization explicitly to analyze the museum processes to which collections have been subject, making visible the internal transactions of the museum that are so often occluded (Kräutli 2016: 215-217). A key aspect is absence. Priestley was perhaps the first maker of visualizations to note how the "thin and void places" in a chart are significant in their own right (Priestley 1764: 24; Boyd Davis 2019). Trouillot (2015: 25) identifies the multiple opportunities for invisibility in relation to historiography, while Klein highlights the importance of such "archival silence" in visible records (Klein 2013). She particularly argues the need to use the visible as merely a starting point for contextualized inquiry that may include actively seeking lost data, lost connections and the forces that may have produced them. This is an important way in which visual externalization can become a motive force, rather than merely a mechanism, in humanities research.

Through gaining a better understanding of the V\&A RPS dataset's qualities with quick prototyping in conversation with stakeholders at the museum, we were prompted to shift direction in the project. Since our focus for this project was to highlight the photographic content rather than institutional practices, we explored visualization design that deliberately did not emphasize the overall shape of the collection.

If one extreme of the feedback loop is not a single individual, neither does the emerging artifact exist in isolation; the designer (and other participants) can be considered as interacting with — and altering-a surrounding culture. Part of this contextual environment is their own ongoing experience: designers "learn a repertoire of concepts, schemas, and strategies," and draw from this repertoire "to design representations and action for unique situations" (Argyris 1985: 81). Second-order cybernetics accounts for this in terms of nested loops which each inform the other (Glanville 2007, Sweeting 2016). In some cases, the interactive context includes the intellectual frameworks, questions and assumptions of academic inquiry. This is the domain of critical making (Ratto 2011) in which "the site of knowledge creation is the process in conversation with a discipline's scholarly research" (Hunter 2018: 173). The application of these ideas to data visualization is discussed in Boyd Davis and Kräutli (2015). This brings us to the final category in our overview of the roles of the external artifact in the design process, which we have already alluded to several times.

\section{Externalization as research}

There is an ever-growing literature of design-as-research. We mention here some key interventions in this field, not always acknowledged. Rust et al. (2000: 403) 


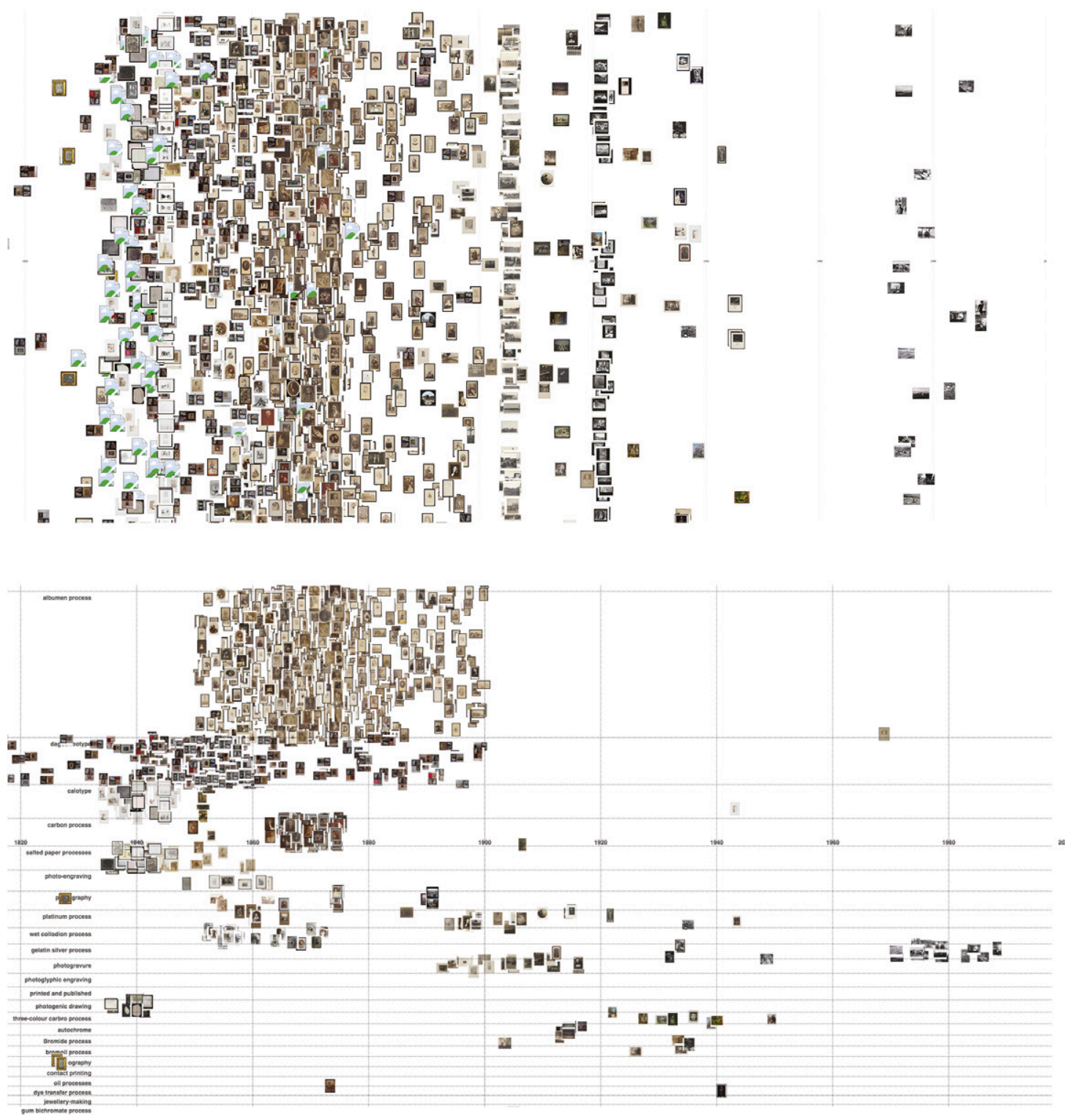

Figure 2. Olivia Vane, 2018. Rough prototypes visualizing the Royal Photographic Society collection at the Victoria \& Albert Museum by a range of attributes. 
highlighted the way design and production of artifacts might be "instrumental in eliciting knowledge". Earlier, Frayling (1993) offered an often-cited triad of relationships between "research into art and design", "research through art and design" and "research for art and design". Although he described his triad as "derived from Herbert Read", he was also building on the work of Archer (1995) who distinguished "research about practice", "research for the purposes of practice" and "research through practice". Of this last, Archer claimed that "there are circumstances where the best or only way to shed light on a proposition, a principle, a material, a process or a function is to attempt to construct something, or to enact something, calculated to explore, embody or test it." We have discussed elsewhere the turn-around in Archer's thinking (Boyd Davis \& Gristwood 2018); given its relevance to our argument, we summarize it here again briefly.

Archer was originally ambitious to turn design into a kind of science. Given his conception of science at the time, he assumed that one begins designing by gathering all the data and the requirements and assigning them appropriate weights. Designs are then developed and tested in a rigorous iterative process leading to a more or less successful solution answering the original requirements. The original problem, question or issue is not however reconsidered. As a result of his experience of complex, multi-stakeholder projects at the intersection of multiple requirements and disciplines, he radically altered his view. He notes that "during the course of the problem solving activity new objectives may tend to form and re-form" (Archer 1968: \$2.29). These are not minor adjustments in the light of changing circumstances, rather, "any effective design procedure must therefore permit radical reappraisal of the problem at any stage" (Archer 1968: \$6: 17, emphasis added). The requirements to which the designers thought they were responding may be subject to revision at almost any point. These changes in his thinking later led Archer to propose a then radical idea: that design is a unique means of interrogating the world, on a par with, and different from, the textual humanities and the sciences (Archer 1979).

Others have developed this theme, all emphasizing the role of the emergent design(s) as instantiation-and elicitation-of knowledge. As Rittel (1972: 392) put it, "the irritating thing is that, depending on the state of solution, the next question for additional information is unique and dependent on the state of solution you have already reached". Problem setting is Schön's (1983) alternative to the conventional emphasis on design as problem solving. This problem-setting may be judged by "the quality and direction of the reflective conversation to which it leads" (p. 135), echoing the conversational model discussed above. For Buchanan (1992: 17) "A quasisubject matter is not an undetermined subject waiting to be made determinate. It is an indeterminate subject waiting to be made specific and concrete". Dorst and Cross (2001) characterize the key role of feedback into the original brief or problem: design involves "constant iteration of analysis, synthesis and evaluation processes between the two notional design 'spaces' - problem space and solution space." The problem space and the solution space co-evolve together, with interchange of information between the two.

To design through the production of artifacts may seem at first sight to be working in the wrong order: surely the question should be pinned down before the answer is attempted? But a key contribution of designing may be to transform or subvert the original question: it may make apparent new possibilities that could not have been foreseen without instantiation through visualization. A tentative design acts not only as a corrective, allowing a poor question or specification to be improved, but also as a provocation-even an inspiration-to further questions. Nowhere is this more 
true than in the visualization of cultural data, where some questions are obvious because they are traditional, but others may be new because the means to ask them were not previously available. This gives the emerging design a key role in research, by provoking or advancing new issues or questions.

In our own practical work, we use externalization in this way-for thinking through the issues and challenges around a project, informing the direction of our work and engaging with stakeholders, and generating new research questions. In a visualization project with the Cooper Hewitt Smithsonian Design Museum, New York City, we were interested to trace themes through time across their digitized collection. One project produced another, because the first made apparent what might be possible in the second. Initially our attention was drawn to tagging in the collection data: informal, descriptive labels used thematically at Cooper Hewitt. To begin with, we experimented with visualizing tags in collection data against time, testing ideas through mock-ups and prototypes (see Figure 3). For instance, we trialed various ways to map the data by time, which was a challenge in this dataset as much of the historical date information was uncertain and/or imprecise, as it so often is (Kräutli \& Boyd Davis 2013; Cottrell 2017).

Throughout this project, we worked closely with staff at the museum. Discussing our timeline prototype with the curators prompted them to suggest that the template we had developed could work well for visualizing the collection by color. Adapting the visualization to color could facilitate tracing color trends and innovations through history. Changing the direction of the project in response to this new area of interest, we developed an interface exhibited by the museum that works with a color search (see Figure 4). We believe the curators would have been unable to foresee the potential for such an interface if they had not been inspired by the earlier prototype.

The new color theme demanded new elements in the user interface design, including a way to select colors to search by. We experimented with mapping an extensive

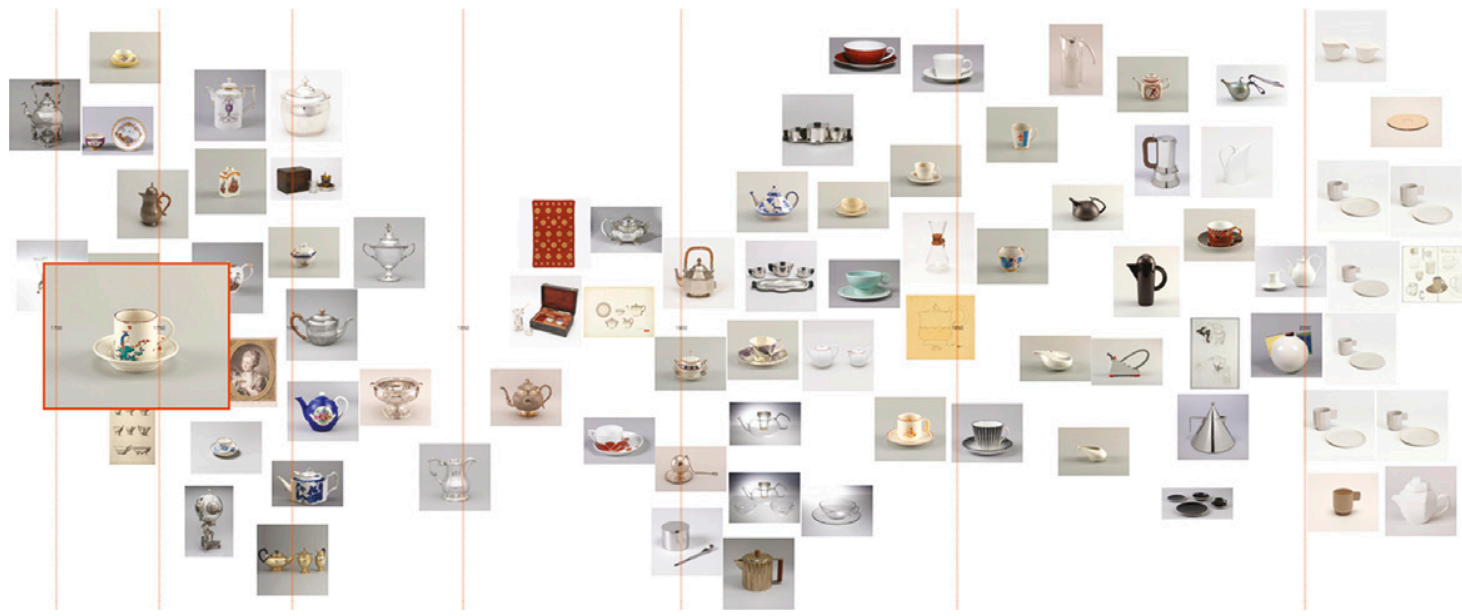

Figure 3. Olivia Vane, 2017. Prototype visualizing items tagged 'coffee and tea drinking' in the Cooper Hewitt Smithsonian Design Museum collection horizontally by date. 


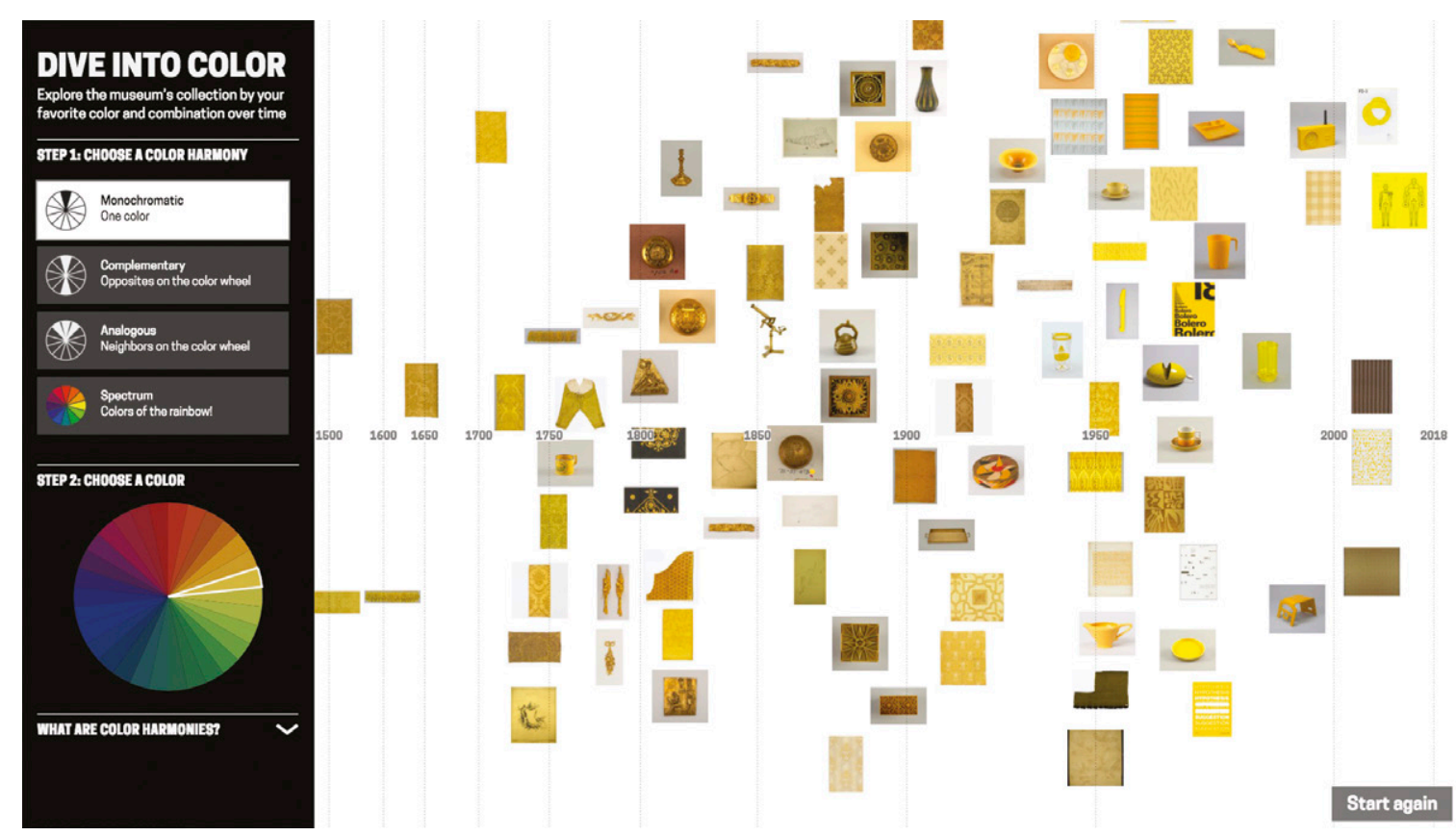

Figure 4. Olivia Vane, 2018. 'Dive into Color', visualizing the Cooper Hewitt Smithsonian Design Museum collection by color and date.

palette of colors to a color wheel, to use as a search input. We trialed various ways to do this: mapping color values as dots round a radial hue map; or drawing circle sectors divided concentrically for the different colors (see Figure 5).

While creating these visual examples, we realized that the sector technique could be applied to an individual item's color palette. Rather than serving as an input, this would be purely informational: the graphic reveals the color wheel relationships between the colors present in the item's palette (see Figure 6). These relationships (for example opposites or neighbors) determine the color relationships (and, therefore, visual effect-balanced or contrasting) exploited in the design-for most users a new way to understand color data in the collection. This was also topical, as the museum curators were working towards an exhibition around color theory and design. The stimulus of the earlier tag-based design and the timely opportunity for novel interrogation and presentation of the collection together had produced a new brief and a new set of research questions.

The color wheel graphic for an individual item's palette became part of the final design, while the original search-input experiments were abandoned for a standard color wheel design. Externalization had prompted us to identify new possibilities by connecting the visual forms we had created for one element of the design to a different element. 

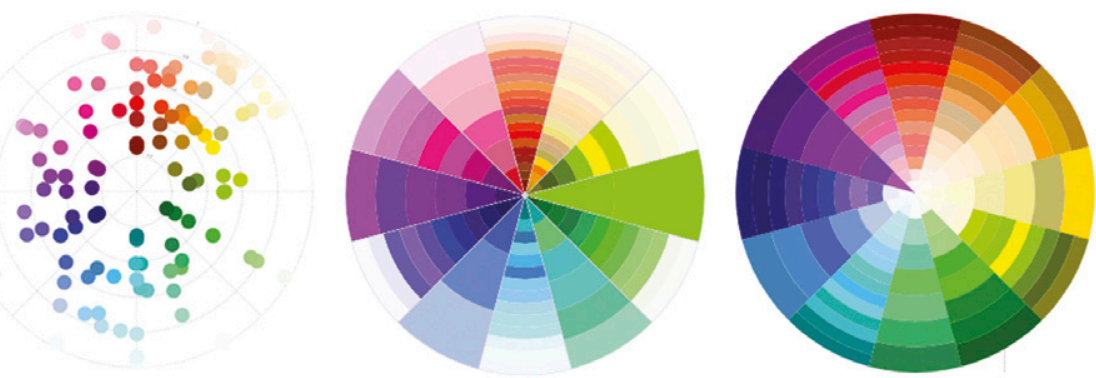

Figure 5. Olivia Vane, 2017. Prototypes mapping a wide color palette to a color wheel
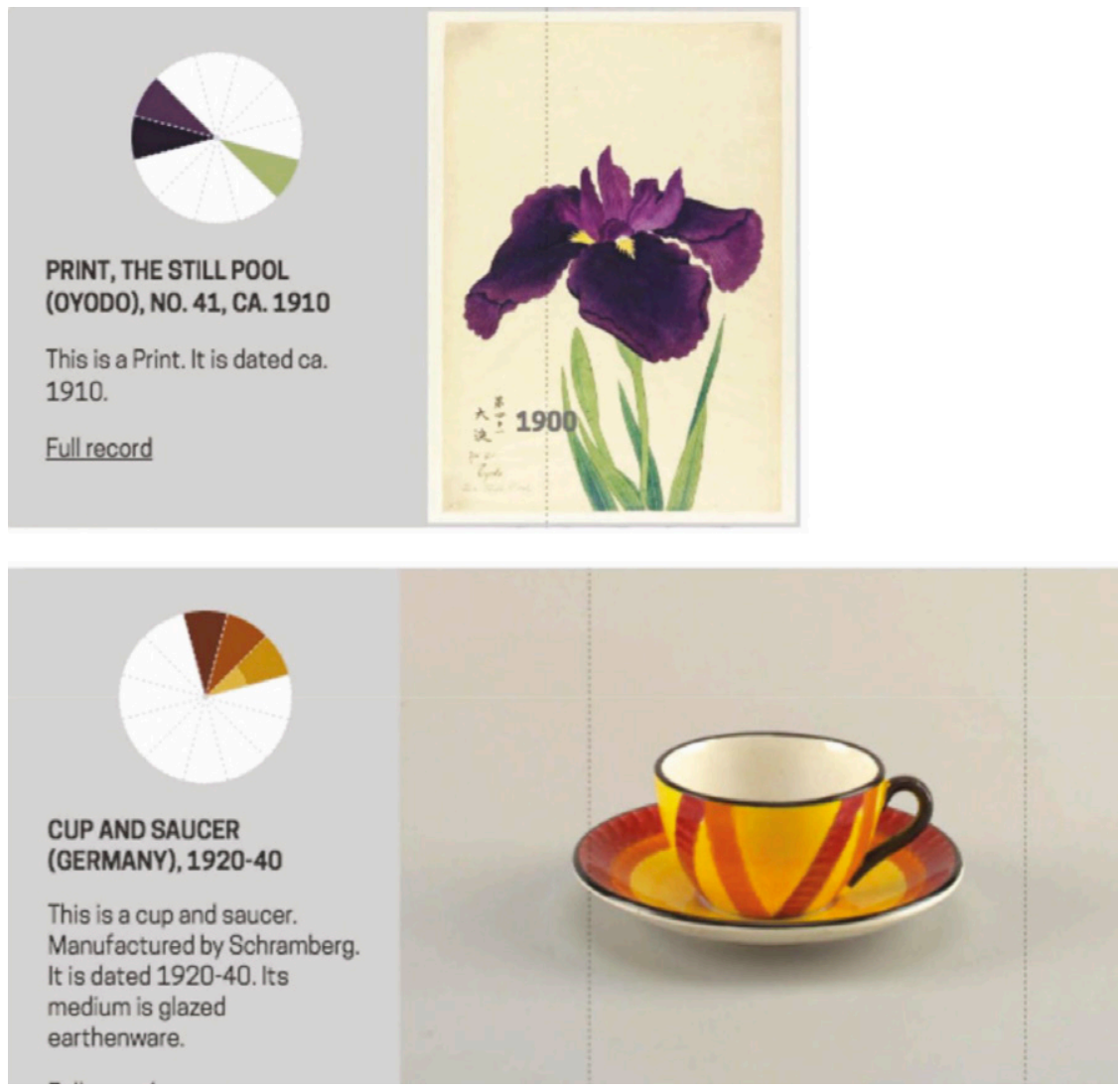

Figure 6. Olivia Vane, 2018. Graphic mapping an item's color palette to a color wheel. Cooper Hewitt Smithsonian Design Museum collection. In the upper example, users can clearly see the use of complementary colors, on opposite sides of the color circle, while in the lower example a very different color harmony arises from the use of adjacent colors. 


\section{Implications}

Among the implications from the theory and practice outlined above, we focus on the designer-as-researcher and the consequences for the overall conceptualization of the design role, including the project specification and skills required.

We noted earlier how the visual has tended to be excluded from debates on digital humanities. The value of externalization is obvious to most readers of this journal but, until recently, the world of digital humanities has been dominated by concerns over relations between just two disciplines-computing and the humanities-and the idea that design may have a fundamental role to play has been neglected. An exception is Drucker, who has highlighted the interpretive role of the visual along her career (e.g., Drucker 1984; 2014) including in collaboration with Nowviskie, where they described their task as to "overcome humanists' long-standing resistance (ranging from passively ignorant to actively hostile) to visual forms of knowledge production" (Drucker \& Nowviskie 2004: 431). Their demand that "The computational processes that serve speculative inquiry must be dynamic and constitutive in their operation, not merely procedural and mechanistic" (ibid) can be considered definitional for our category externalization as research.

Clearly, software development is vital to the life of digital humanities projects, but as Biemann at al. (2014) note, there can be mutual incomprehension between programmers and humanists. Designing is not a key part of Biemann's argument, but the potential for designs to act as common ground between the other disciplines, both enhancing mutual understanding and surfacing new questions, is clear. But designing must be integral to the development of projects from the outset, if the advantages of its contribution to the problem definition or research question are to be realized with full effectiveness.
Submission date: 1 February, 2019

Accepted date: 4 July, 2019

\section{Acknowledgements}

We gratefully acknowledge the support of Olivia Vane's AHRC award AH/L503782/1 through the London Doctoral Design Centre and AHRC International Placement Scheme award AH/ P002722/1. Our thanks also for the support of the Wellcome Library, Cooper Hewitt Smithsonian Design Museum, the Victoria \& Albert Museum and the National Swedish Heritage Board. We are also grateful for the insightful comments of the anonymous reviewers.

\section{References}

van Amstel, F. M. C., Hartmann, T., van der Voort, M. C., \& Dewulf, G. P. M. R. (2016). The social production of design space. Design Studies, 46. 199-225. https://doi.org/10.1016/j.destud.2016.06.002

Archer, L. B. (1968). The structure of design processes. Doctoral thesis. London: Royal College of Art. Available on British Library Ethos (ID: 697935). Also available on RCA Research Repository.

Retrieved from http://researchonline.rca.ac.uk/2949/.

Archer, L. B. (1979). Design as a discipline. Design Studies, 1(1), 17-20. https://doi.org/10.1016/0142-694X(79)90023-1

Archer, L. B. (1995). The nature of research. Co-design, 6-13.

Arnheim, R. (1993). Sketching and the psychology of design. Design Issues, 9(2), 15-19. https://doi.org/10.2307/1511669

Argyris, C., Putnam, R., \& McLain Smith, D. (1985). Action Science. San Francisco: Jossey-Bass.

Bailey, J., \& Pregill, L. (2014). Speak to the eyes: The history and practice of information visualization. Art Documentation, 33(2), 168-191. https://doi.org/10.1086/678525

Berners-Lee, T. J. (1989). Information management: A proposal. CERN-DD-89-001-OC. Geneva: CERN.

Bertin, J. (1967). Sémiologie graphique. Paris: Mouton/ Gauthier-Villars.

Biemann, C., Crane, G. R., Fellbaum, C. D., \& Mehler, A. (2014). Computational humanities: Bridging the gap between 
computer science and digital humanities (Dagstuhl Seminar 14301). Dagstuhl Reports, 4(7).

https://doi.org/10.4230/DagRep.4.7.80

Boyd Davis, S. (2019). Time machines. In: J. Pilcher (Ed.), Culture, technology and the image. Bristol: Intellect Books. 52-70.

Boyd Davis, S., \& Gristwood, S. (2018). 'A dialogue between the real-world and the operational model': the realities of design in Bruce Archer's 1968 doctoral thesis. Design Studies, 56, 185-204. https://doi.org/10.1016/j.destud.2017.11.005

Boyd Davis, S., \& Kräutli, F. (2015). The idea and image of historical time: Interactions between design and digital humanities. Visible Language, 49(3) [Special issue 'Critical making: Design and the digital humanities'], 100-119.

Buchanan, R. (1992). Wicked problems in design thinking. Design Issues, 8(2), 5-21.

Bush, V. (1945). As we may think. The Atlantic Monthly, July 1945.

Cockburn, A., Karlson, A., \& Bederson, B. B. (2009). A review of overview+detail, zooming, and focus+context interfaces. ACM Computing Surveys, 41(1). https://doi.org/10.1145/1456650.1456652

Cottrell, S. (2017). Understanding textual uncertainty in dates using interactive timelines. Proc. Electronic Visualisation and the Arts, EVA 2017 (pp. 68-73). London: British Computer Society. https://doi.org/10.14236/ewic/EVA2017.13

Crilly, N., Maier, A., \& Clarkson, P. J. (2008). Representing artefacts as media: Modelling the relationship between designer intent and consumer experience. International Journal of Design, 2(3), 15-27.

Dávila, P. (2017). Visualization as assemblage. Information Design Journal, 23(1) ['Information Visualization'], 19-31. https://doi.org/10.1075/idj.23.1.04dav

Dörk, M., Pietsch, C., \& Credico, G. (2017). One view is not enough: High-level visualizations of a large cultural collection. Information Design Journal, 23(1), 39-47. https://doi.org/10.1075/idj.23.1.06dor

Dorst, K., \& Cross, N. (2001). Creativity in the design process: Coevolution of problem-solution. Design Studies, 22(5), 425-437. https://doi.org/10.1016/So142-694X(01)00009-6

Drucker, J. (1984). Letterpress language: Typography as a medium for the visual representation of language. Leonardo, 17(1), 8-16. https://doi.org/10.2307/1574850

Drucker, J. (2014). Graphesis: the visual production of knowledge in a digital era. Cambridge, MA: Harvard University Press.
Drucker, J., \& Nowviskie, B. (2004). Speculative computing: Temporal modelling. In: S. Schreibman, R. Siemens, \& J. Unsworth (Eds.), A companion to digital humanities (pp. 431-447). Oxford: Blackwell Publishers.

Engelbart, D. C. (1962). Augmenting human intellect: A conceptual framework. Summary Report AFOSR-3233. Menlo Park, CA: Stanford Research Institute.

Frayling, C. (1993). Research in art and design. Royal College of Art Research Papers, 1(1). London: Royal College of Art.

Glanville, R. (2007). Try again. Fail again. Fail better: The cybernetics in design and the design in cybernetics. Kybernetes, 36(9/10), 1173-1206. https://doi.org/10.1108/03684920710827238

Glanville, R., \& Pak, B. (2010). Quasi entailment mesh. European Meetings on Cybernetics and Systems Research. University of Vienna, 6-9 April 2010. [n.p.].

Goldschmidt, G. (1991). The dialectics of sketching. Creativity Research Journal, 4(2), 123-143. https://doi.org/10.1080/10400419109534381

Goody, J. (1987). The Interface between the written and the oral. Cambridge: Cambridge University Press.

Havelock, E. A. (1986). The muse learns to write. New Haven, CT: Yale University Press.

Hunter, E. B. (2018). Building video game adaptations of dramatic and literary texts. In L. Levenberg, T. Neilson, \& D. Rheams (Eds.), Research methods for the digital humanities (pp. 173-194). London: Palgrave Macmillan.

Hutchins, E. (1999). Cognitive artifacts. In R. A. Wilson \& F. C. Keil (Eds.), MIT Encyclopedia of the Cognitive Sciences (pp. 126-127). Cambridge, MA: MIT Press.

Jänicke, S. (2016). Valuable research for visualization and digital humanities: A balancing act. Workshop on Visualization for the Digital Humanities, VisWeek, Hilton Baltimore hotel, Baltimore, Maryland, USA, 23-28 October 2016.

Kimbell, L. (2011). Rethinking design thinking: Part I. Design and Culture, 3(3), 285-306. https://doi.org/10.2752/175470811X13071166525216

Klein, L. F. (2013). The image of absence: Archival silence, data visualization, and James Hemings. American Literature, 85(4), 661-688. https://doi.org/10.1215/00029831-2367310

Kräutli, F. (2016). Visualising cultural data: Exploring digital collections through timeline visualisations. PhD thesis, Royal 
College of Art, London.

Retrieved from http://researchonline.rca.ac.uk/1774/

Kräutli, F., \& Boyd Davis, S. (2013). Known unknowns:

Representing uncertainty in historical time. In $\mathrm{K} . \mathrm{Ng}$, J.

P. Bowen, \& S. McDaid (Eds.), Proceedings of EVA London,

British Computer Society, London, 29-31 July 2013 (pp. 61-68). London: British Computer Society.

Lloyd, D., \& Dykes, J. (2011). Human-centered approaches in geovisualization design: Investigating multiple methods through a long-term case study. IEEE Transactions on Visualization and Computer Graphics, 17(12), 2498-2507. https://doi.org/10.1109/TVCG.2011.209

MacEachren, A. M. (2001). An evolving cognitive-semiotic approach to geographic visualization and knowledge construction. Information Design Journal, 10(1), 26-36.

Nelson, T. H. (1974). Computer lib / Dream machines.[Self-published].

Noël, G. (2014). Design education: Creating diagrams to help students understand complex problems. Information Design Journal, 21(2), 88-98. https://doi.org/10.1075/idj.21.2.02noe

Norman, D. A. (1991). Cognitive artifacts. In J. M. Carroll (Ed.), Designing interaction. Cambridge, MA: Cambridge University Press.

Ong, W. J. (1982). Orality and literacy: The technologizing of the word. London: Methuen \& Co.

Pask, G., Kallikourdis, D., \& Scott, B. C. E. (1975). The representation of knowables. International Journal for Man-Machine Studies, 7(1), 15-134. https://doi.org/10.1016/Soo20-7373(75)80003-4

Priestley, J. (1764). A description of a chart of biography. Warrington: British Library General Reference Collection.

Ratto, M. (2011). Critical making: Conceptual and material studies in technology and social life. Information Society, 27(4), 252-26o. https://doi.org/10.1080/01972243.2011.583819

Rittel, H. (1972) On the planning crisis: Systems analysis of the 'first and second generations'. Bedriftsøkonomen, 8, 390-396.

Rudd, J., Stern, K., \& Isensee, S. (1996). Low vs. high-fidelity prototyping debate. Interactions, 3(1), 76-85. https://doi.org/10.1145/223500.223514

Rust, C., Hawkins, S., Whiteley, G., Wilson, A., \& Roddis, J. (2000). Knowledge and the artefact. In D. Durling, \& K. Friedman (Eds.), Proceedings of Doctoral Education in Design Conference (pp. 395-404). La Clusaz, France, 8-12 July 2000.

Scaife, M., \& Rogers, Y. (1996). External cognition: How do graphical representations work? International Journal of
Human-Computer Studies, 45, 185-213.

https://doi.org/10.1006/ijhc.1996.0048

Schön, D. A. (1983). The reflective practitioner: How professionals think in action. New York: Basic Books.

Simon, H. A. (1956). Rational choice and the structure of the environment. Psychological Review, 63(2), 129-138. https://doi.org/10.1037/hoo42769

Spivey, M. J. (2007). Redesigning our theories of human information processing. Information Design Journal, 15(3), 261-265.

Staley, D. (2017). On the "maker turn" in the humanities. In J. Sayers (Ed.), Making things and drawing boundaries: Experiments in the digital humanities (Debates in the digital humanities). Minneapolis: University of Minnesota Press.

Stevens, J. (2013). Design as communication in microstrategy: Strategic sensemaking and sensegiving mediated through designed artifacts. Artificial Intelligence for Engineering Design, Analysis and Manufacturing, 27(2), 133-142. https://doi.org/10.1017/So890060413000036

Sweeting, B. (2016). Design research as a variety of second order cybernetic practice. Constructivist Foundations, 11(3), 572-579.

Thompson Klein, J. (2017). The boundary work of making in digital humanities. In J. Sayers (Ed.), Making things and drawing boundaries: Experiments in the digital humanities (Debates in the Digital Humanities). Minneapolis: University of Minnesota Press.

Trouillot, M. R. (2015). Silencing the past: Power and the production of history (2nd ed.). Boston: Beacon.

Vane, O. (2019). Cultural visualisation and the value of simplicity. Europeana Tech Insight, 11: Generous Interfaces. Retrieved from https://pro.europeana.eu/page/ issue-11-generous-interfaces

Visser, W. (2006). The cognitive artifacts of designing. Mahwah, NJ: Lawrence Erlbaum Associates.

Warde, B. (2009). The crystal goblet, or why printing should be invisible. In H. Armstrong (Ed.), Graphic Design Theory: readings from the field (pp. 39-43). New York: Princeton Architectural Press.

Whitelaw, Mitchell. (2015). Generous interfaces for digital cultural collections. Digital Humanities Quarterly, 9(1), Retrieved from http://www.digitalhumanities.org/dhq/ $\mathrm{vol} / 9 / 1 / 000205 / 000205 . h t m$ 


\section{About the authors}

Professor of Design Research at the Royal College of Art, Stephen Boyd Davis connects research in the history of visualization to the development of new, digital practice. His specialism is the visual representation of historical time, focusing on

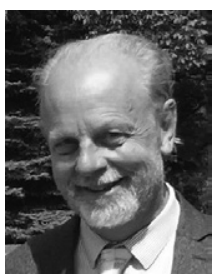
the relation between diagrammatic form and conceptions of time, history, and narrative. He is also investigating the origins of design research as a discipline, with particular emphasis on the systematic design methods movement of the 1960 s and the subsequent shift towards the proposition that design is a third way of understanding and dealing with the world, alongside the sciences and humanities. He is an advisor on research quality to universities and other organizations internationally.

Email: stephen.boyd-davis@rca.ac.uk
Olivia Vane is a $\mathrm{PhD}$ candidate in Innovation Design Engineering at the Royal College of Art, where she explores how interactive data visualization can be used to make sense of cultural heritage data (digitized museum, library and archive collections). She has worked with institutions including

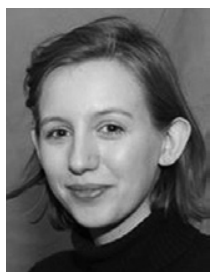
the Victoria \& Albert Museum, the Wellcome Library, and the Swedish National Heritage Board. During her $\mathrm{PhD}$, she completed a Smithsonian Fellowship at the Cooper Hewitt Design Museum, New York City.

Email: olivia.fletcher-vane@network.rca.ac.uk 